\title{
Analysis of Educational Game Design Approach based on Learning Motivation
}

\author{
Xiaoxiao Cao, Yangchao Cai, Yu Shen \\ Hangzhou Business School, Zhejiang Gongshang University, Hangzhou, 310012, China
}

Keywords: Learning Motivation, Educational Games, Design Way

\begin{abstract}
After the new curriculum reform, in order to respond to the call of the national quality education, conform to the trend of the times, the education community begins to try to infiltrate the game theory into teaching practice, to stimulate students' learning motivation with play education. Based on learning motivation, this paper analyzes the educational games, and expounds the design principles and specific measures of the educational games proceed from the learning motivation, hoping to improve the overall level of education in our country and promote the further development of quality education.
\end{abstract}

\section{Introduction}

As our economic development, and the further improvement of information technology level, the games gradually become one of the indispensable entertainment for young people in today's society, to some extent, it causes that some self-poor students easily get lost in the play of electronic game, which have a bad influence on learning. The community is in fear of the future development of the youth, at the same time, also begins to work on the analysis of the true cause why the games are gaining significant traction among the youth. They hope that the game ideas can penetrate into the teaching field and realize edutainment, to improve China's overall level of education.

\section{The basic connotation of learning motivation}

The learning motivation is that to stimulate the individual to participate in the game, to maintain the game activities which have been carried out, and ultimately to promote the development of individual learning activities in the internal mechanism of learning objectives. In the social life, any of the activities people participated in point to a specific target under the inspiration of a certain motivation, so do the learning motivation and learning activities. there is a specific interaction between the two. In the learning process, the learners can have a great influence on the learning motivation, such as the spiritual needs, learning interest and related emotions, the specific content of which will be involved in the curiosity, the sense of achievement, interest and sense of competence, etc..

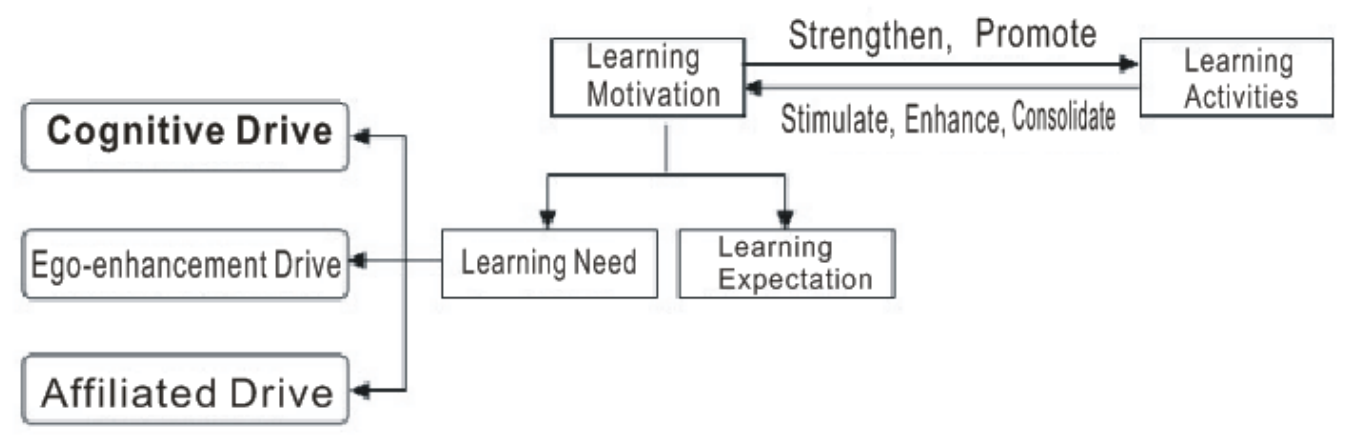

Fig 1. The basic connotation of learning motivation

Above, the basic connotation of learning motivation, from the connotation of the diagram you can see that the learning need and learning motivation are two important elements, and the interaction 
between the two together make up the learning motivation system. Ausubel, a famous psychologist, points out that in the study, the school should have some influence on the students' learning needs, and the following questions need attention: cognition, self-improvement and subsidiary the three aspects of inner driving force, and in different age, the three important parts have different effect on the learners. Learning expectation refers to the estimation of the subjective level of the learning objectives in the relevant learning activities, and the most important role is to produce a kind of internal incentive for students' learning activities ${ }^{[1]}$. At the same time, in the process of stimulating students learning motivation, we should pay attention to the complexity of learning motivation, different factors may have different effects on students' learning effect. Therefore, the teachers should choose the motivation types according to the learning motivation, which can stimulate students' learning interest and promote students' comprehensive development.

\section{Educational games and the incentive effect educational games have}

Famous Dutch scholar Johan Huizinga gave a more objective analysis of the characteristics of the game in his book People: Player, he pointed out that the game was what human individual made a voluntary activity or pastime in the social life, and such activities or leisure pastime is carried out within the established time and space, and the rules of the game are what the players are willing to accept in the process to participate in the game with absolutely binding ${ }^{[2]}$. The purpose of the game is to the activity itself, but also can make people nervous, happy and other spiritual awareness different from daily life in the process of participation in the games. In the analysis of John Huizinga's, we can conclude that: the game is what the player do consciously and voluntary rather than forced by outside pressure, so it has the corresponding voluntary nature; the game is carried out in a certain time and space, if leave the specific time and space, the game will lose its basis, so it has the time and space; the player can get nervous and pleasure the two completely different emotional experience in the course of the game, so it has strong feelings; there are some differences between the game and other activities in daily life, it is a kind of social reality imitation; the purpose of gaming activities is the game itself, not to any other object, so it has autonomy.

For the important part of the education game in the game, it refers to a kind of game with a feature of game and educational functions at the same time, and it can create by the corresponding virtual situation, to stimulate students' curiosity for learning life, encourage learners to actively explore the relevant game activities, and ultimately to participate in the activities of the game. Through a strong knowledge and fun game, to inspire the cognitive of the learners in the learning process, and through the continuous upgrading and strengthening of the game to meet the needs of learners self-excavation and self-achievement, it can eventually help learners get enough in their own attribution and the need of recognition. It can be said that the application of educational games can produce an extremely strong attraction to the learners in the learning and practice, and then the motivation to stimulate and sustain the learners to participate in learning activities, and to improve the teaching effect ${ }^{[3]}$. Malouf and other used the method of contrast test to study the problem, and it is clear that the education game can effectively maintain the learning motivation of the learners. In this study randomly selected 25 students, participated in the experimental group game teaching activities and participate in the control group, the basic teaching activities of students, after the completion of the experimental study found students in the experimental group compared with the control group in the continuity of learning skills upgrading has obvious superiority. And Terrell, Rendulic, Tuzun Hakan, et al. comparative study also confirmed that the education game can produce a positive impact on students learning motivation. 


\section{The basic design principles of educational games Rule diversity principle}

Not a radius of no rules, educational games are effected by their own enjoyment and game-play, so it takes advantages of their own education under the scientific rules of the game, to ensure that students participate in the game in a fair competition environment, to achieve good learning results. In the educational games involved in the virtual environment of education, learners must ensure that their participation in the process of the game can consciously follow the rules of the game, and promote the smooth development of educational games. At the same time, in different types and modes of the game, it should be based on the characteristics of the game and the need to set up the quality of students to set up a personalized game rules, to ensure that educational games can maximize their educational advantages.

\section{The principle of plot reasonableness}

If the relevant game design department want to ensure that the game design to meet the development of the game to meet the educational objectives, it should be scientific and reasonable choice and design of the game, to ensure that students in the process of participating in the game to learn from the relevant knowledge points, and to participate in the skills training, so that students in a pleasant emotional experience, more easy to learn relevant knowledge points, and gradually enhance students' participation in learning activities.

\section{The principle of induction factors richness}

Learning motivation generally contains three aspects of the influence factors, that is, the intrinsic needs of motivation, external environmental incentives and the corresponding self adjustment. And the installation of outside incentive in the three plays a strong supporting role on the learning motivation of the students. It can be seen from the analysis and research of general game, except the most basic feature of interest and integral in the game, rewards and extrinsic incentives are the main factors to encourage students to continue to participate in the games and activities . In the education stage, the development of students' personality is not perfect, which is easy to be influenced by external factors. So, in the design of educational games, you can set a certain incentive program, to stimulate the passion of the students to participate in the education game .

\section{The principle of full integration of game plot and educational content}

The game plot and education content are two most important factor in educational game design, which will be the key and difficult point of current educational game design. In practice, the relevant game designers can design on the basis of the content of the study, so that the game can truly and perfectly combine with the teaching content ${ }^{[4]}$. For example, in the task teaching, game designers can design the corresponding game tasks according to the teaching task, to ensure that after the students complete the relevant game tasks, the teaching task will be completed, to improve the learning effect; in the role play teaching, according to the game, designers can set up different game image, so that students can fully experience the game characters in the process of completing the game tasks , enhance the fun and openness of the classroom teaching, to lay the foundation for the future development of students.

It is an important way to design the teaching content combined with the games. With the further development of computer information technology, the application of more advanced computer technology to design the game activities, can put the game and education content together more perfect, to stimulate students' learning motivation, at the same time, to improve teaching effect.

\section{Educational game design strategy based on learning motivation Analysis for the adaptive object of design activities}

Because there are huge differences in their own cognitive style and learning interest of the learners in different age influenced by the the law of growth and development, so the scientific education 
game design should take all types of adaptation into account. To stimulate students' learning motivation through the education game, for example, because the students' cognitive and practical ability are relatively poor, so the process of game design should pay attention to the age characteristics of primary school students, and cognitive characteristics, and to design the relevant educational games based on these characteristics for primary school teaching.

\section{Analysis of teaching objective}

Good educational games must have specific teaching goals, and promote the development of educational games to complete the task of the whole teaching task. It can be said that the whole education game design project is to allow learners to complete the task of learning in a relaxed free game process, to obtain the training of learning skills, and then achieve the overall teaching objectives. In the primary stage of the students, influenced by the students' growth law, the students' attention on class is not long time, very easy to be influenced by external factors, at this time if the game target design is not reasonable, not clear, students will be difficult to learn to think, but simply to participate in the game, not only can't conducive the learning motivation, but even the future development of students is effected. So in the education game design, the analysis of the teaching objectives should be served as the basis of the whole work, with the most appropriate teaching objectives, to enhance the quality of integrated education game design.

\section{The choice of teaching content}

Relevant educational game design personnel should be in strict accordance with the learner's own characteristics and different teaching objectives to choose and set up teaching content. For primary school students, because the students' thinking ability is relatively strong, and the abstract thinking ability is poor, so the teaching content should refer to the recent development area theory, ensuring a strong image, and easy for students to understand, appropriate increase the content of the image, so that in the premise of setbacks education, they will not produce a sense of frustration, they will learn that we could make it by efforts in the learning process, and further strengthen their self-confidence, improve teaching effect. The choice of the content of this kind of educational game, can make the students to complete the learning task in the excited state, and then actively participate in the teaching activities, it is useful for the overall development of students ${ }^{[5]}$.

\section{Provide the study guide}

The learning guide is also an important part of educational game design. In the primary stage of the education game design process, because of the learners' ability of abstract thinking and logical thinking are relatively poor, so the design of educational games must be able to provide students for the corresponding learning guide, so that it can actively put into the game learning life. When the students are confused with the relevant rules of the game, the education game guide should guide students in a timely manner, to help students to participate in the game, the game task. At the same time, we should pay attention to the actual design process of the educational game, but also should take into account the characteristics of the development of the students, in the environment, the choice of the game plot to meet the actual needs of different learners, and promote the comprehensive development of students.

\section{The real-time feedback of game information}

Psychological research shows that the real-time learning information feedback comes from the learning results has an important impact on the promotion of learning effect of students. On the one hand, the students can adjust their learning strategies according to the guidance of the feedback information. On the other hand, the recognition of the feedback information can further stimulate the students' learning interest, and to maintain a positive and stable learning state in the later period. 


\section{Conclusion}

With the rapid development of computer information technology in today's society, educational games for its own superiority has gradually been the attention of the community, loved by the students and their parents. Therefore, at this stage, the relevant education departments should strengthen the exploration of the educational game design. Based on the learning motivation, to stimulate students' learning enthusiasm, so that the students can participate in educational activities in a better state. Further improvement of the teaching effect, to lay the foundation for the future development of students as well as the improvement of the overall level of education in china.

\section{References}

[1] Xu Zhen,Liu Weilong. Research on the design strategy of educational game from the perspective of learning motivation. Software Tribune, 2015(4):178-180.

[2] Cai A'Xiang. Research on the design of educational game software based on learning motivation theory. Henan Normal University, 2011.

[3] Xie Kai, Ma Yingfeng. Research on the motivation matching tactic of educational game -- the fusion research on game motivation and learning motivation based on intrinsic motivation theory. Chinese Educational informational Higher Vocational Education, 2013(1):49-52.

[4] Cui Yong. Research on the design and development of safety education game based on the theory of Situated Cognition -- Taking the fire safety as an example. Zhejiang Normal University, 2013.

[5] Jiao Chenwei. The design and development of primary school English education game-- Taking Aisa castle as an example. Yangzhou University, 2013. 